\title{
Aconine inhibits RANKL-induced osteoclast differentiation in RAW264.7 cells by suppressing NF-KB and NFATc1 activation and DC-STAMP expression
}

\author{
Xiang-zhou ZENG ${ }^{1,2}$, Long-gang $\mathrm{HE}^{1}$, Song WANG ${ }^{3}$, Keng WANG ${ }^{1}$, Yue-yang ZHANG ${ }^{1}$, Lei TAO ${ }^{1}$, Xiao-juan LI $\mathrm{LI}^{1, *}$, Shu-wen LIU ${ }^{1,}$ * \\ ${ }^{1}$ School of Pharmaceutical Sciences, Southern Medical University, Guangzhou 510515, China; ${ }^{2}$ College of Pharmacy, Hainan Medical \\ University, Haikou 571199, China; ${ }^{3}$ Department of Surgery, Guangdong Hospital of Traditional Chinese Medicine, Guangzhou 510120, \\ China
}

\begin{abstract}
Aim: Aconiti Lateralis Radix Preparata is a traditional Chinese medicine used to treat chronic arthritis and is highly effective against rheumatoid arthritis. However, the effects of aconine, a derivative of aconitum alkaloids, on osteoclasts, which can absorb bone, remain unknown. Here, we investigated the effects of aconine on osteoclast differentiation and bone resorption in vitro.

Methods: The viability of mouse leukemic monocyte/macrophage cell line RAW264.7 was measured using CCK-8 assays. Osteoclast differentiation was induced by incubation of RAW264.7 cells in the presence of RANKL, and assessed with TRAP staining assay. Bone resorption was examined with bone resorption pits assay. The expression of relevant genes and proteins was analyzed using RT-PCR and Western blots. The activation of NF-kB and nuclear factor of activated T-cells (NFAT) was examined using stable NF-kB and NFATc1 luciferase reporter gene systems, RT-PCR and Western blot analysis.

Results: Aconine $(0.125,0.25 \mu \mathrm{mol} / \mathrm{L})$ did not affect the viability of RAW264.7 cells, but dose-dependently inhibited RANKL-induced osteoclast formation and bone resorptive activity. Furthermore, aconine dose-dependently inhibited the RANKL-induced activation of NF-KB and NFATc1 in RAW264.7 cells, and subsequently reduced the expression of osteoclast-specific genes (c-Src, 33 -Integrin, cathepsin K and MMP-9) and the expression of dendritic cell-specific transmembrane protein (DC-STAMP), which played an important role in cell-cell fusion.

Conclusion: These findings suggest that aconine inhibits RANKL-induced osteoclast differentiation in RAW264.7 cells by suppressing the activation of NF-KB and NFATc1 and the expression of the cell-cell fusion molecule DC-STAMP.
\end{abstract}

Keywords: aconine; osteoclast; RAW264.7; bone resorption; NF-kB; NFATc1; DC-STAMP; osteoporosis; rheumatoid arthritis

Acta Pharmacologica Sinica (2016) 37: 255-263; doi: 10.1038/aps.2015.85; published online 23 Nov 20152016

\section{Introduction}

Bone homeostasis is maintained through the balance between bone formation by osteoblasts and bone resorption by osteoclasts. Imbalance caused by excessive bone resorption leads to bone loss in skeletal diseases, such as osteoporosis, lytic bone metastases, and rheumatoid arthritis (RA) ${ }^{[1]}$.

Osteoclasts are unique bone-resorbing and multinucleated cells that form from the monocyte-macrophage lineage of hematopoietic stem cells ${ }^{[1]}$ through cell fusion, which is

\footnotetext{
* To whom correspondence should be addressed.

E-mail lixiaoj@smu.edu.cn (Xiao-juan LI);

liusw@smu.edu.cn (Shu-wen LIU)

Received 2015-05-15 Accepted 2015-08-27
}

regulated by fusion molecules such as dendritic cell-specific transmembrane protein (DC-STAMP) ${ }^{[2]}$. Osteoclast differentiation and function are regulated by a variety of systemic hormones and cytokines. Among these, receptor activator of nuclear factor (NF)- $\mathrm{kB}$ ligand (RANKL) is a major osteoclastogenic molecule. The binding of RANKL to receptor activator of nuclear factor (NF)-KB (RANK) leads to the recruitment of tumor necrosis factor receptor-associated factor 6 (TRAF6), which triggers activation of mitogen-activated protein kinase (MAPK) [extracellular signal-regulated (ERK), c-Jun N-terminal kinase (JNK) and p38] and transcription factors, such as NF- $\mathrm{kB}$, activator protein $1(\mathrm{AP}-1)$ and nuclear factor of activated T-cells (NFAT) ${ }^{[3,4]}$. The activities of these transcription factors consequently regulates osteoclast differentiation by upregulating the expression of osteoclast-associated genes, such 
as tartrate-resistant acid phosphatase (TRAP), cathepsin K, $\beta 3$-Integrin and DC-STAMP ${ }^{[5]}$.

During the differentiation of osteoclasts, the fusion of mononuclear pre-osteoclasts is a critical event during the formation of mature multinucleated osteoclasts ${ }^{[6]}$. Fusion failure can result in the severe reduction of bone-resorbing activity and an increase in bone mass, as seen in osteopetrosis ${ }^{[7]}$. DCSTAMP plays an essential role in the fusion of mononuclear osteoclasts ${ }^{[8]}$. DC-STAMP-deficient cells can not develop into multinucleated osteoclasts, and resorption pit formation is consequently inhibited ${ }^{[9]}$. These findings demonstrate the importance of DC-STAMP in osteoclast differentiation and bone remodeling.

Aconiti Lateralis Radix Preparata is a traditional Chinese medicine commonly used to treat chronic arthritic diseases ${ }^{[10]}$ that has a well-known therapeutic effect against rheumatoid $\operatorname{arthritis}^{[11]}$. During its medicinal use in clinics, Aconiti Lateralis Radix Preparata must usually be boiled for a long time to remove toxins, which hydrolyzes its poisonous component, aconitine, first into the much less toxic benzoylaconine and then into the almost non-toxic aconine ${ }^{[12]}$. Because bone destruction in RA is related to increased bone resorption, inhibiting osteoclastogenesis and/or decreasing bone resorptive activity in mature osteoclasts are promising approaches for treating bone resorption-related disorder ${ }^{[13]}$. However, whether aconine regulates osteoclast formation and function has not yet been reported.

Therefore, in this study, we investigated a potential role for aconine in the inhibition of differentiation and bone resorption activity in osteoclasts and the molecular mechanisms underlying these processes.

\section{Materials and methods Materials}

Aconine (purity $>98 \%$ by HPLC; Figure $1 \mathrm{~A}$ ) was purchased from Chengdu Must Bio-Technology Co, Ltd (Chengdu, China). Dulbecco's modified Eagle's medium (DMEM), fetal bovine serum (FBS), penicillin and streptomycin were purchased from Gibco (Rockville, MD, USA). The Cell Counting Kit-8 (CCK-8) was obtained from Dojindo Molecular Technologies (Japan). Soluble recombinant RANKL was obtained from R\&D (Lorton, VA, USA). Leukocyte Acid Phosphatase (TRAP) Kits, cyclosporin A (CsA) and BAY11-7082 were obtained from Sigma-Aldrich (St Louis, MO, USA). Osteo Assay Surface 96-well plates were obtained from Corning Life Science (St Lowell, MA, USA). ІкB- $\alpha$ antibodies, NF-кB p65 (C22B4) rabbit $\mathrm{mAb}$ and $\beta$-actin (13E5) rabbit $\mathrm{mAb}$ were purchased from Cell Signaling (Beverly, MA, USA). Anti-DC-STAMP (clone 1A2) was purchased from Millipore (Billerica, MA, USA). Lamin B1 antibodies were purchased from Bioworld Technology (Minneapolis, MN, USA). RAW264.7 cells transfected with luciferase reporter constructs under the control of NF-kB or NFATc1-binding promoter elements were kindly provided by Prof Jiake XU (University of Western Australia, Nedlands, WA 6009, Australia).

\section{Cell culture}

RAW264.7 cells, a mouse leukemic monocyte/macrophage cell line, were purchased from the American Type Culture Collection (Manassas, VA, USA) and were maintained in DMEM supplemented with $10 \%$ heat-inactivated FBS, penicillin (100 units $/ \mathrm{mL})$ and streptomycin $(100 \mu \mathrm{g} / \mathrm{mL})$ at $37^{\circ} \mathrm{C}$ in a humidified $5 \% \mathrm{CO}_{2}$ atmosphere.

\section{Cytotoxicity assays}

To evaluate the effect of aconine on the viability of RAW264.7 cells, cytotoxicity assays were performed using the Cell Counting Kit-8 according to the manufacturer's instructions. Briefly, the cells were seeded in 96-well plates at a density of $2 \times 10^{4}, 3 \times 10^{3}, 1.2 \times 10^{3}, 1 \times 10^{3}$ or $1 \times 10^{3}$ cells/well in the presence or absence of aconine $(0.125-0.5 \mathrm{mmol} / \mathrm{L})$ for $8 \mathrm{~h}, 24 \mathrm{~h}, 48 \mathrm{~h}, 5$ $\mathrm{d}$ or $7 \mathrm{~d}$, respectively. After incubating the cells with CCK-8 solution for $2 \mathrm{~h}$, optical density was measured at $450 \mathrm{~nm}$ using a GENios microplate reader (Tecan, Austria). Cell viability was expressed as a percentage of the control.

\section{In vitro osteoclastogenesis assays}

To generate osteoclasts, RAW264.7 cells $\left(1 \times 10^{3}\right.$ cells/well $)$ were cultured in the presence of $100 \mathrm{ng} / \mathrm{mL}$ of RANKL and aconine at a concentration of 0.125 or $0.25 \mathrm{mmol} / \mathrm{L}$. After $4 \mathrm{~d}$, cells were fixed in $4 \%$ paraformaldehyde for $10 \mathrm{~min}$ and then stained for TRAP activity according to the manufacturer's instructions. TRAP-positive multinucleated (nuclei>3) cells $\left(\mathrm{TRAP}^{+} \mathrm{MNCs}\right)$ were scored as osteoclasts using a light microscope (IX71; Olympus) ${ }^{[14]}$.

\section{Bone resorption pit assays}

RAW264.7 cells $\left(1 \times 10^{3}\right.$ cells/well) suspended in DMEM containing $10 \% \mathrm{FBS}$, penicillin (100 units/mL) and streptomycin $(100 \mu \mathrm{g} / \mathrm{mL})$, were seeded in Corning Osteo Assay Surface 96-well plates coated with calcium phosphate substrate in the presence of $100 \mathrm{ng} / \mathrm{mL}$ RANKL and different concentrations of aconine $(0.125$ and $0.25 \mathrm{mmol} / \mathrm{L})$. The cells were incubated at $37{ }^{\circ} \mathrm{C}$ in $5 \% \mathrm{CO}_{2}$ for $7 \mathrm{~d}$, and the medium was changed every $3 \mathrm{~d}$. After $7 \mathrm{~d}$, cells were washed with a $10 \%$ bleach solution. Images of resorption pits on the plates were captured using a light microscope (IX71; Olympus) and quantified using Image-Pro Plus 6 software, and the results were expressed as a percentage of the total plate area ${ }^{[15]}$.

\section{Luciferase reporter gene assays of NF-KB or NFATc1}

To examine the inhibitory effects of aconine on NF- $\mathrm{kB}$ and NFATc1 activation, RAW264.7 cells transfected with luciferase reporter constructs controlled by NF-kB or NFATc1-binding promoter elements were plated in 96-well plates at a density of $1 \times 10^{4}$ cells/well. Cells were pretreated with aconine and the NF-KB inhibitor, BAY11-7082, or the NFAT inhibitor, CsA, for $30 \mathrm{~min}$ and then stimulated with $100 \mathrm{ng} / \mathrm{mL}$ of RANKL in the presence of aconine and BAY11-7082 or CsA for $8 \mathrm{~h}$. At the end of the culture period, cells were rinsed twice with PBS and lysed with $1 \times$ lysis buffer $(20 \mu \mathrm{L} /$ well). Luciferase activity was measured using a luciferase assay system according to the 
manufacturer's instructions (Promega, Madison, WI, USA) ${ }^{[14,16]}$.

\section{Real-time PCR analysis}

RAW264.7 cells $\left(2 \times 10^{6}\right.$ cells/well) were seeded in a 6-well plate, pretreated with varying concentrations of aconine $(0.125$ and $0.25 \mathrm{mmol} / \mathrm{L}$ ) for $2 \mathrm{~h}$, and then treated with RANKL $(100 \mathrm{ng} / \mathrm{mL})$ in the absence or presence of aconine for $24 \mathrm{~h}$.

Total RNA was isolated using TRIzol reagent (Invitrogen Carlsbad, CA, USA). For RT-PCR, single-stranded cDNA was synthesized from $1 \mu \mathrm{g}$ of total RNA using reverse transcriptase (TaKaRa Biotechnology, Otsu, Japan). Real-time PCR was performed using SYBR ${ }^{\circledR}$ Premix Ex Taq ${ }^{\mathrm{TM}}$ II (Tli RNaseH Plus) (TaKaRa Biotechnology) and results were detected using an ABI 7500 Sequencing Detection System (Applied Biosystems, Foster City, CA, USA). PCR amplification was performed using the following program: $95^{\circ} \mathrm{C}$ for $30 \mathrm{~s}$ and then 40 cycles of $95^{\circ} \mathrm{C}$ for $5 \mathrm{~s}$ and $60^{\circ} \mathrm{C}$ for $34 \mathrm{~s}$. Primers were designed against the following mouse sequences: NFATc1 (forward: GGGTCAGTGTGACCGAAGAT, reverse: GGAAGTCAGAAGTGGGTGGA), c-Src (forward: CCAGGCTGAGGAGTGGTACT, reverse: CAGCTTGCGGATCTTGTAGT), $\beta 3$-Integrin (forward: TGACATCGAGCAGGTGAAAG, reverse: GAGTAGCAAGGCCAATGAGC), Cathepsin K (forward: GGCCAACTCAAGAAGAAAAC, reverse: GTGCTTGCTTCCCTTCTGG), MMP-9 (forward: AGTTTGGTGTCGCGGAGCAC, reverse: TACATGAGCGCTTCCGGCAC), DCSTAMP (forward: TCCTCCATGAACAAACAGTTCCAA, reverse: AGACGTGGTTTAGGAATGCAGCTC), GAPDH (forward: AACTTTGGCATTGTGGAAGG, reverse: ACACATTGGGGGTAGGAACA) $)^{[17,18]}$. Data were analyzed by the $2^{-\Delta \Delta C T}$ method, and all values were normalized to the level of the housekeeping gene, GAPDH.

\section{Protein preparation and Western blot analysis}

RAW264.7 cells were seeded in 6-well plates at a density of $2 \times 10^{6}$ cells/well and incubated for $24 \mathrm{~h}$. Cells were then pretreated with or without different concentrations of aconine for $30 \mathrm{~min}$ followed by stimulation with $100 \mathrm{ng} / \mathrm{mL}$ RANKL in the absence or presence of aconine for $30 \mathrm{~min}$ (to detect IкB- $\mathrm{a}$ and NF-kB p65) or $24 \mathrm{~h}$ (to detect DC-STAMP). Whole cell lysates were prepared from cultured cells using RIPA buffer ( $50 \mathrm{mmol} / \mathrm{L}$ Tris-HCl, pH 7.5, $150 \mu \mathrm{mol} / \mathrm{L}$ sodium chloride, $0.5 \%$ cholic acid, $0.1 \%$ SDS, 2 mmol/L EDTA, $1 \%$ Triton, and $10 \%$ glycerol) containing protease and phosphatase inhibitors $(1 \mathrm{mmol} / \mathrm{L}$ phenylmethylsulfonyl fluoride, $1 \mathrm{mmol} / \mathrm{L}$ $\mathrm{Na}_{3} \mathrm{VO}_{4}$, and $\left.1 \mathrm{mmol} / \mathrm{L} \mathrm{NaF}\right)^{[19]}$. Fractionation of cytoplasmic and nuclear protein was performed using NE-PER Nuclear and Cytoplasmic Extraction Reagents (Pierce Biotechnology, Rockford, IL, USA) according to the manufacturer's protocol. Samples of whole cell extracts and subcellular fractionated extracts were normalized to determine protein concentrations using the BCA method. Cytoplasmic and whole cell extracts (30 $\mu \mathrm{g}$ each) and nuclear extracts $(15 \mu \mathrm{g})$ were separated by $10 \%$ SDS-PAGE and electrotransferred to polyvinylidene difluoride membranes (Bio-Rad, Hercules, CA, USA). After blocking in $5 \%$ nonfat milk for $1 \mathrm{~h}$, the membranes were incu- bated with the indicated primary antibodies at $4{ }^{\circ} \mathrm{C}$ overnight. Finally, membranes were incubated with a horseradish-peroxidase (HRP)-conjugated secondary antibody for $1 \mathrm{~h}$, developed using the ECL system (Cell Signaling) and then exposed to X-ray film (Kodak). The films were scanned and quantified using Quantity One software (Bio-Rad, USA).

\section{Statistical analysis}

All data were analyzed using GraphPad Prism 5.0 software. The results are representative of three independent experiments consisting of three replicates per experiment and expressed as the mean \pm SEM. One-way ANOVA followed by Dunnett's Multiple Comparison Test was used to test significant differences. In all cases, $P<0.05$ was considered to be statistically significant.

\section{Results}

\section{Aconine suppresses RANKL-induced osteoclastogenesis}

To examine the effect of aconine on RANKL-induced osteoclastogenesis, we incubated RANKL-treated RAW264.7 cells with various concentrations of aconine and then evaluated the formation of osteoclasts. RAW264.7 cells cultured in the presence of RANKL formed TRAP ${ }^{+}$MNCs. However, aconine treatment reduced the number of RANKL-induced osteoclasts in a dose-dependent manner (Figure 2A and 2B). These data thus suggest that aconine inhibited RANKL-induced osteoclastogenesis. To exclude the possibility that the observed inhibitory effect of aconine on osteoclastogenesis might be due to cytotoxicity, a cytotoxicity assay was performed using RAW264.7 cells (Figure 1B). We found that aconine had no cytotoxic effect on osteoclast precursor cells at the concentrations used in this study.

\section{Aconine attenuates bone resorption in vitro}

Treatment with aconine was shown to reduce the area of osteoclast bone resorption pits in a dose-dependent manner (Figure $3 \mathrm{~A}$ and $3 \mathrm{~B}$ ). This result suggests that aconine attenuates the bone resorptive activity of osteoclasts in vitro.

\section{Aconine suppresses RANKL-induced osteoclast-associated gene expression}

To further explore the role of aconine in osteoclast differentiation, we analyzed the mRNA expression levels of RANKLinduced osteoclast-associated genes in the absence or presence of aconine. The mRNA expression levels of c-Src, $\beta 3$-Integrin, cathepsin K and MMP-9 were suppressed by aconine in a dose-dependent manner during osteoclastogenesis (Figure 4). These results support the idea that aconine inhibits osteoclastogenesis and bone resorption.

\section{Aconine suppresses RANKL-induced activation of NF-KB}

To determine the underlying mechanism involved in the inhibitory effect of aconine, we first focused on whether aconine suppresses RANKL-induced NF-KB activation. An inhibitory effect of aconine on the activation of NF-KB was revealed in experiments using luciferase activity assays. RANKL 
A

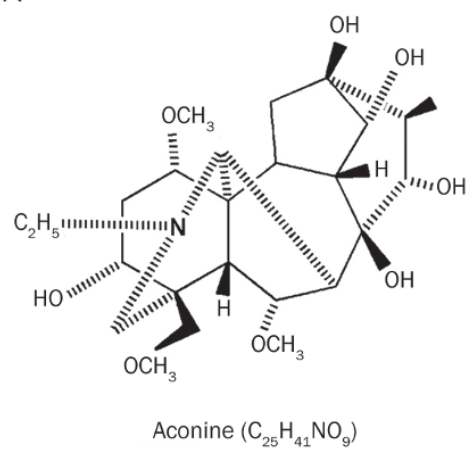

B

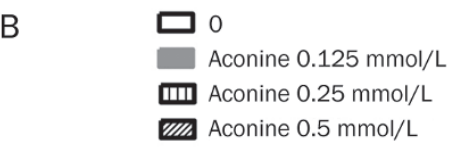

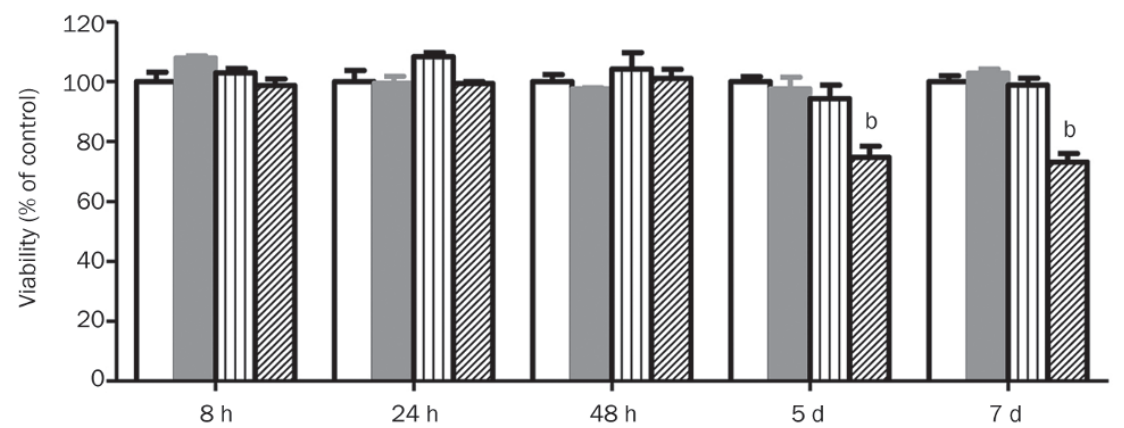

Figure 1. Effect of aconine on the viability of RAW264.7 cells. (A) The chemical structure of aconine. (B) Effect of aconine on the viability of RAW264.7 cells. The cytotoxic effect of aconine was evaluated using the CCK-8 method. RAW264.7 cells were cultured for $8 \mathrm{~h}, 24 \mathrm{~h}, 48 \mathrm{~h}, 5 \mathrm{~d}$ or $7 \mathrm{~d}$ in the presence or absence of varying concentrations of aconine. Optical density was measured at $450 \mathrm{~nm}$. Cell viability was expressed as a percentage of the control. Mean \pm SEM. $n=3 .{ }^{\mathrm{b}} P<0.05$ vs control.

significantly induced the transcriptional activity of NF- $\mathrm{kB}$ in RAW264.7 cells that were stably transfected with NF-kB-luc. In contrast, treatment with aconine and the NF-KB inhibitor, BAY11-7082, significantly inhibited the RANKL-induced transcriptional activity of NF-KB in a dose-dependent manner (Figure 5A). These results suggest that aconine might inhibit the RANKL-induced NF-KB signaling pathway and thereby contribute to the suppression of osteoclast formation. To further confirm this finding, IкB- $\alpha$ expression and NF-кB p65 translocation were assessed by Western blot analysis using whole, cytosolic or nuclear extracts. Treatment with RANKL decreased the expression of IKB- $\alpha$ in whole extracts and increased the level of NF-kB p65 in nuclear extracts. However, treatment with aconine for 30 min followed by stimulation with RANKL for $30 \mathrm{~min}$ attenuated the RANKL-induced deg-

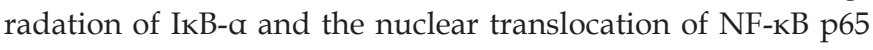
(Figure 5B).

\section{Aconine inhibits RANKL-induced NFATc1 activation}

Activation of NF-KB is important for the initial induction
A

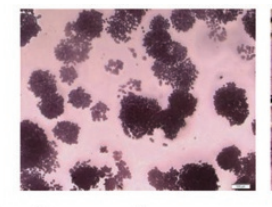

Aconine

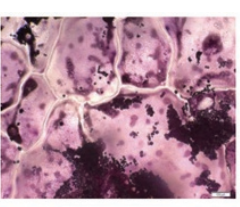

0

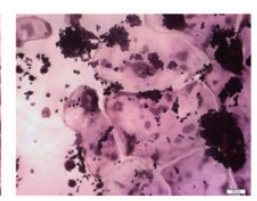

$0.125 \mathrm{mmol} / \mathrm{L}$

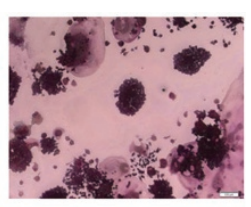

$0.25 \mathrm{mmol} / \mathrm{L}$

RANKL $100 \mathrm{ng} / \mathrm{mL}$

B

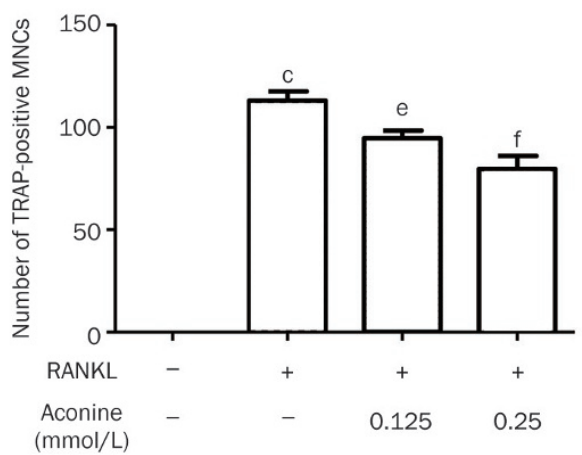

Figure 2. Aconine inhibits RANKL-induced osteoclast differentiation. (A) RAW264.7 cells were cultured for $4 \mathrm{~d}$ with RANKL (100 ng/mL) in the presence of varying concentrations of aconine and then stained for TRAP activity. Representative photomicrographs were taken under a light microscope (magnification $\times 100$ ). (B) TRAP-positive cells containing more than three nuclei were counted as osteoclasts. Mean \pm SEM. $n=3$. ${ }^{c} P<0.01$ vs control; ${ }^{\mathrm{e}} \mathrm{P}<0.05,{ }^{\mathrm{f}} \mathrm{P}<0.01$ vs only RANKL-treated cells. 


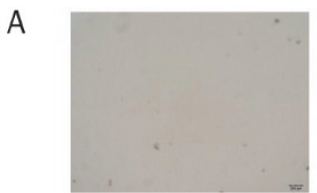

Aconine 0

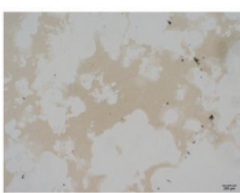

0

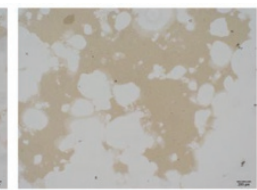

$0.125 \mathrm{mmol} / \mathrm{L}$

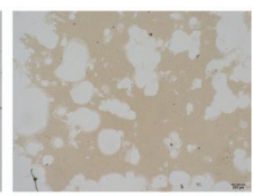

$0.25 \mathrm{mmol} / \mathrm{L}$

RANKL $100 \mathrm{ng} / \mathrm{mL}$

B

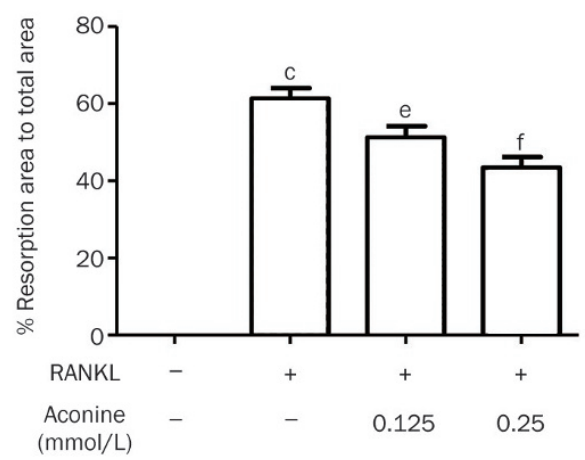

Figure 3. Aconine inhibits RANKL-induced osteoclastic bone resorption. RAW264.7 cells were seeded in Osteo Assay Surface 96-well plates overnight and treated with RANKL $(100 \mathrm{ng} / \mathrm{mL})$ in the presence of the indicated concentrations of aconine for $7 \mathrm{~d}$. Cells attached to the plates were removed. (A) Resorption pits on the plates were captured using a light microscope (IX71; Olympus) (magnification $\times 100)$. (B) Resorption areas were quantified using Image-Pro Plus 6 software. Mean \pm SEM. $n=3$. ${ }^{\mathrm{C}} P<0.01$ vs control; ${ }^{\mathrm{e}} P<0.05,{ }^{\mathrm{f}} P<0.01$ vs only RANKL-treated cells.
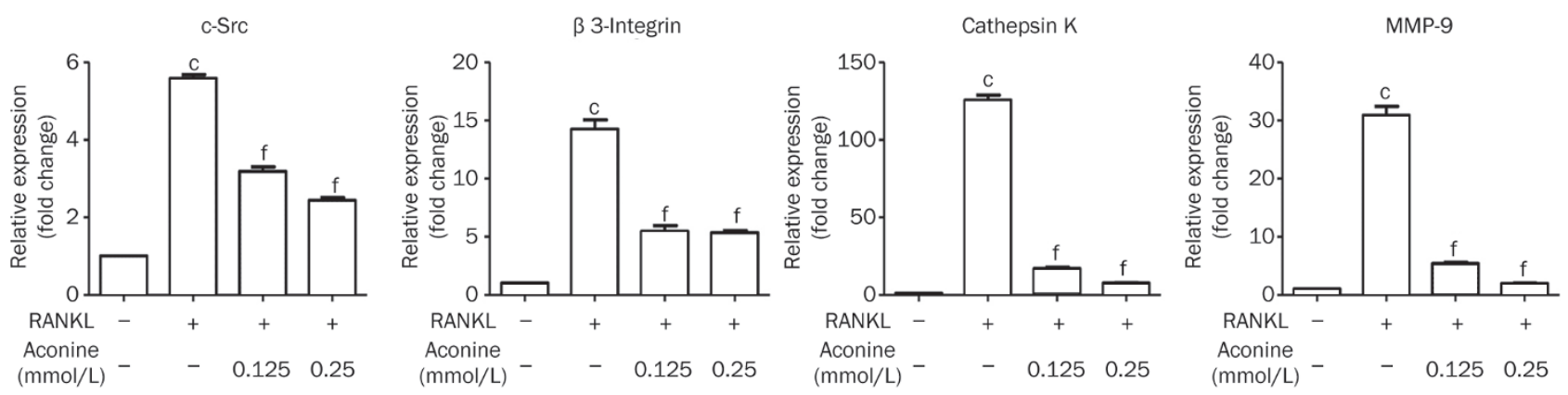

Figure 4. Aconine inhibits the RANKL-induced mRNA expression of osteoclast-specific genes. RAW264.7 cells were pretreated with varying concentrations of aconine for $2 \mathrm{~h}$ and then treated with RANKL $(100 \mathrm{ng} / \mathrm{mL})$ for $24 \mathrm{~h}$. The mRNA expression levels of osteoclast-specific genes were analyzed using real-time PCR. Mean \pm SEM. $n=3 .{ }^{\circ} P<0.01$ vs control; ${ }^{e} P<0.05,{ }^{f} P<0.01$ vs only RANKL-treated cells.

of NFATc1 ${ }^{[20]}$. Because aconine can suppress the RANKLinduced activation of NF-KB, we investigated whether aconine could reduce the activation of NFATc1 in RAW264.7 cells during osteoclastogenesis. NFATc1 was increased at the mRNA level by treatment with RANKL. However, treatment with aconine ( 0.125 and $0.25 \mathrm{mmol} / \mathrm{L})$ significantly inhibited NFATc1 mRNA (Figure 6A). In addition, we also examined NFATc1 transcriptional activity using a luciferase assay system. The NFAT inhibitor, CsA, dramatically inhibited the RANKL-induced transcriptional activity of NFATc1. Meanwhile, treatment with aconine significantly suppressed the RANKL-induced transcriptional activity of NFATc1 in a dosedependent manner (Figure 6B).

\section{Aconine down-regulates the essential fusion molecule DC-STAMP} To determine whether the inhibitory effect of aconine on osteoclast formation results from the suppression of cell-cell fusion, the expression of the fusion protein DC-STAMP was examined using real-time PCR and Western blot analysis. After $24 \mathrm{~h}$ of cell culture, real-time PCR results (Figure 7A) showed a decrease in DC-STAMP mRNA expression in cells treated with aconine after RANKL stimulation. After treatment with aconine for $24 \mathrm{~h}$, DC-STAMP protein levels were also reduced as compared with the RANKL control (Figure 7B).

\section{Discussion}

Excessive activation of osteoclasts causes bone loss in most adult skeletal diseases, including osteoporosis and rheumatoid 


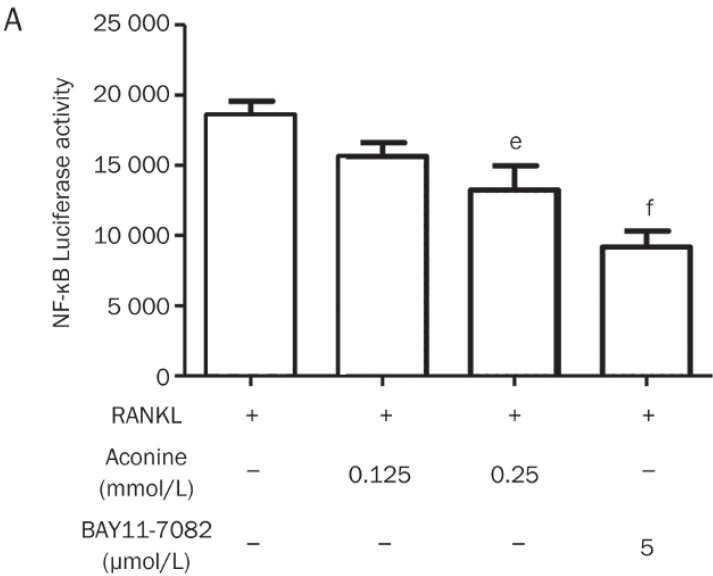

B
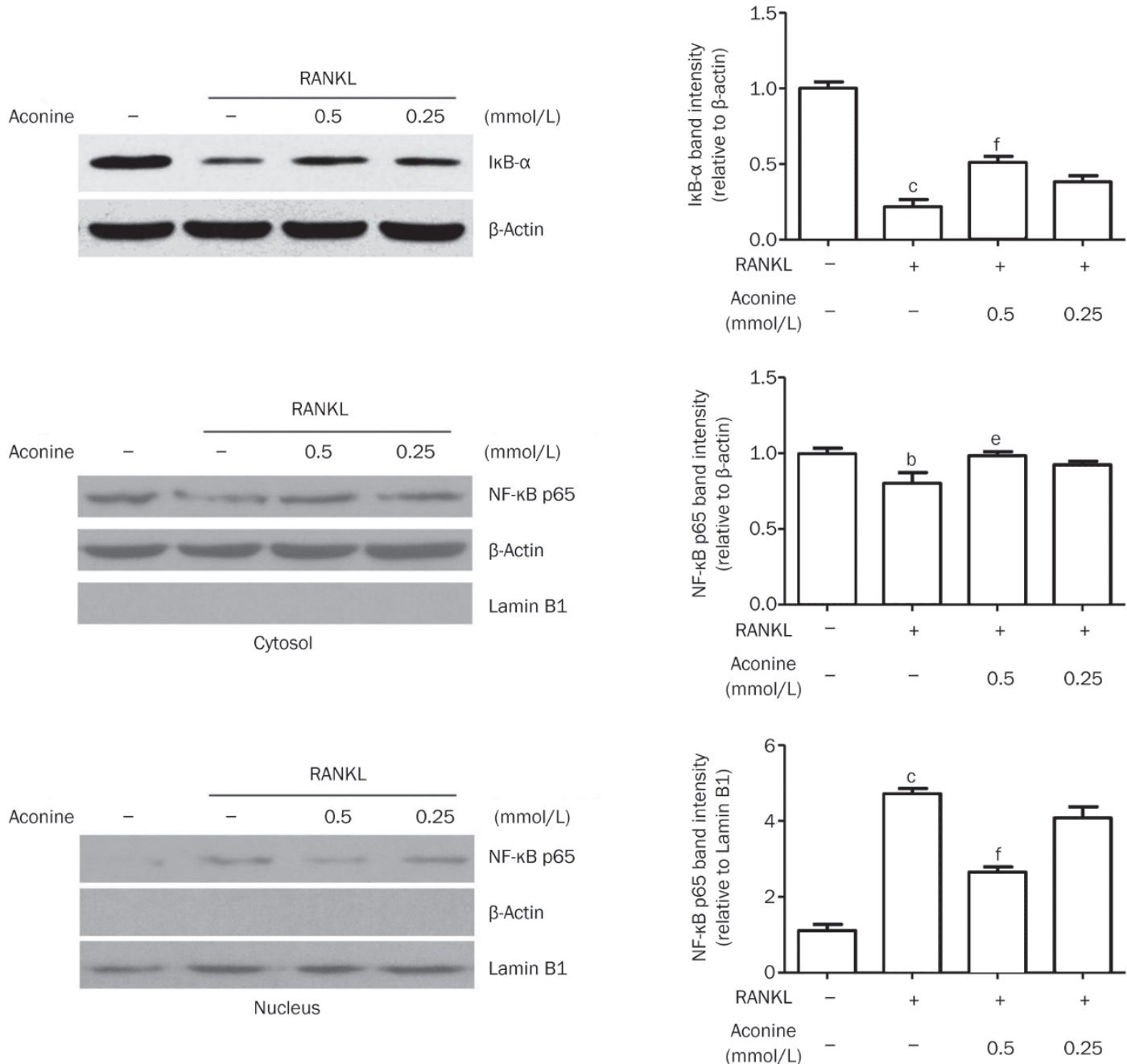

Figure 5. Aconine inhibits RANKL-induced NF-KB activation. (A) RAW264.7 cells that were stably transfected with a NF-kB luciferase reporter construct were pretreated with varying concentrations of aconine and the NF-KB inhibitor, BAY11-7082, for 30 min and then treated with RANKL (100 ng/mL) for $8 \mathrm{~h}$. (B) RAW264.7 cells were pretreated with aconine for $30 \mathrm{~min}$ prior to RANKL (100 ng/mL) stimulation for 30 min. Then, whole cytoplasmic and nuclear proteins were extracted as described in the methods. The expression levels of IkB- $\alpha$, NF-KB p65 in the cytoplasmic and NF-kB p65 in the nuclear extracts were determined using Western blot analysis. Subcellular fraction purity and the equality of sample loading were evaluated by analyzing the levels of $\beta$-actin and Lamin B1. Protein levels were quantified using densitometry. Mean \pm SEM. $n=3 .{ }^{b} P<0.05,{ }^{\mathrm{c}} P<0.01$ vs control; ${ }^{\mathrm{e}} P<0.05,{ }^{\mathrm{f}} P<0.01$ vs only RANKL-treated cells. 
arthritis ${ }^{[1]}$. Accordingly, the down-regulation of osteoclast differentiation or function is a promising target for treatments for such pathologic bone diseases. In this study, we observed that aconine, an effective and non-toxic component of Aconiti Lateralis Radix Preparata, inhibited osteoclast differentiation and bone resorption and we describe a potentially new mechanism for Aconiti Lateralis Radix Preparata related to its traditional use for treating RA.

RAW264.7 cells are commonly used as osteoclast precursors and they can differentiate into osteoclasts in response to RANKL. Without stimulation, RAW264.7 cell will only proliferate. After successful RANKL stimulation, RAW264.7 cells preferred to differentiate into osteoclasts instead of proliferating. In this study, we first observed that RANKL induced TRAP-positive osteoclast formation and bone resorption in pre-osteoclastic RAW264.7 cells were inhibited by aconine (Figure 2 and 3) without cytotoxic effects. Therefore, we further studied the underlying mechanisms involving aconine in osteoclast differentiation and function.

NF-KB signaling has been shown to play an essential role in osteoclastogenesis $^{[21]}$. Therefore, suppression of NF-KB activation could play an important role in osteoclast formation. Luciferase reporter gene assays and Western blot analysis showed that treatment with aconine reduced RANKL-induced NF-KB activation (Figure 5A and 5B). These findings indicated that the down-regulation of RANKL-induced NF-KB signaling pathways might be involved in the suppressive effect by aconine against osteoclastogenesis.

It is generally accepted that during osteoclastogenesis, NFATc1, which belongs to the NFAT transcription superfamily, is an essential transcription factor that regulates RANKLinduced osteoclastogenic gene expression. In the present study, we found that aconine treatment reduced RANKLinduced NFATc1 activation in a luciferase activity assay (Figure 6B). This is consistent with evidence showing that aconine suppresses the RANKL-induced mRNA expression of NFATc1 (Figure 6A).

A

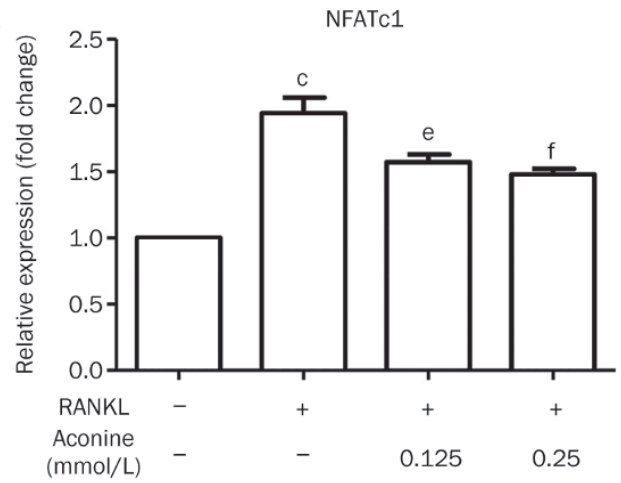

NFATc1 is a downstream nuclear transcription factor that plays a key role in regulating the expression of many osteoclast-specific genes, such as c-Src, $\beta 3$-Integrin, cathepsin $\mathrm{K}$ and MMP- $9^{[4,22]}$, which are involved in the regulation of osteoclast differentiation, fusion and activation. The adhesion molecules $\beta 3$-Integrin and c-Src play important roles in regulating bone resorption of osteoclasts by mediating their migration and adhesion activities ${ }^{[23,24]}$. It has also been reported that osteoclasts deficient for c-Src exhibited reduced motility and abnormal organization in the ruffle border and that they lacked the cytoskeletal elements necessary for bone resorption ${ }^{[23]}$. Therefore, c-Src is required for osteoclastic bone resorption ${ }^{[20]}$. Cathepsin K and MMP-9 degrade the organic bone matrix and contribute to bone resorptive activity ${ }^{[2,26]}$. In this study, we found that treatment with aconine suppressed the expression of these osteoclast-specific genes. Therefore, aconine may suppress osteoclastogenesis by down-regulating the expressions of these genes by decreasing this important nuclear factor. However, the reason that aconine shows a much stronger inhibitory effect on these genes than NFATc1 during osteoclast formation and bone resorption is not clear. Further studies will be needed in the future.

During osteoclastogenesis, cell-cell fusion is a critical step in the development of multinucleated osteoclasts that determines osteoclast size and enhances its resorptive capacity ${ }^{[9,27]}$. DCSTAMP is an essential molecule for mononuclear osteoclast fusion and giant cell formation ${ }^{[9]}$ that increases the absorbing activity of osteoclasts ${ }^{[8]}$. An anti-DC-STAMP monoclonal antibody strongly inhibited osteoclast formation in vitro ${ }^{[28]}$. In this study, we found that treatment with aconine reduced the RANKL-induced expression of DC-STAMP at both the mRNA and protein levels. These results suggest that inhibiting RANKL-induced expression of the fusion molecule DCSTAMP might also contribute to the inhibitory effect of aconine on RANKL-induced osteoclast differentiation and resorption activity.

Taken together, these results suggest that aconine dose-

B

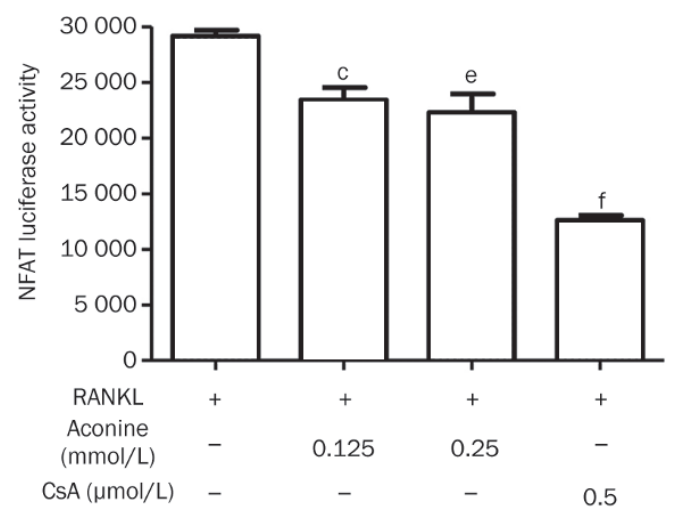

Figure 6. Aconine inhibits RANKL-induced NFATc1 activation. (A) RAW264.7 cells were pretreated with varying concentrations of aconine for $2 \mathrm{~h}$ and then treated with RANKL $(100 \mathrm{ng} / \mathrm{mL})$ for $24 \mathrm{~h}$. NFATc1 mRNA levels were analyzed using real-time PCR. (B) RAW264.7 cells that were stably transfected with an NFATC1 luciferase reporter construct were pretreated with varying concentrations of aconine and the NFAT inhibitor, CSA, for 30 min and then treated with RANKL (100 ng/mL) for 8 h. Mean \pm SEM. $n=3$. ${ }^{b} P<0.05,{ }^{c} P<0.01$ vs control; ${ }^{e} P<0.05,{ }^{f} P<0.01$ vs only RANKL-treated cells. 
A

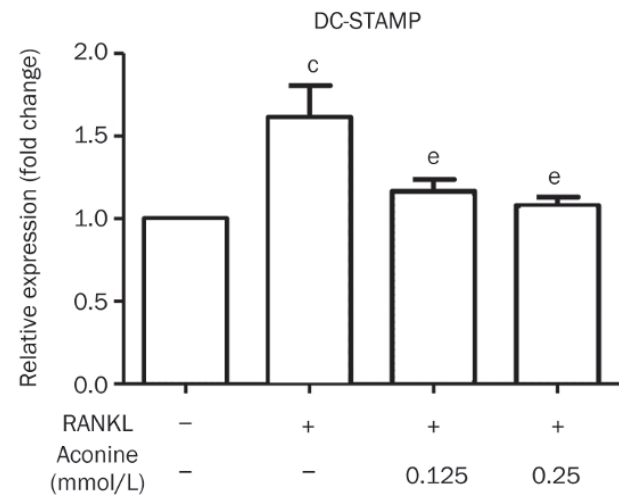

B
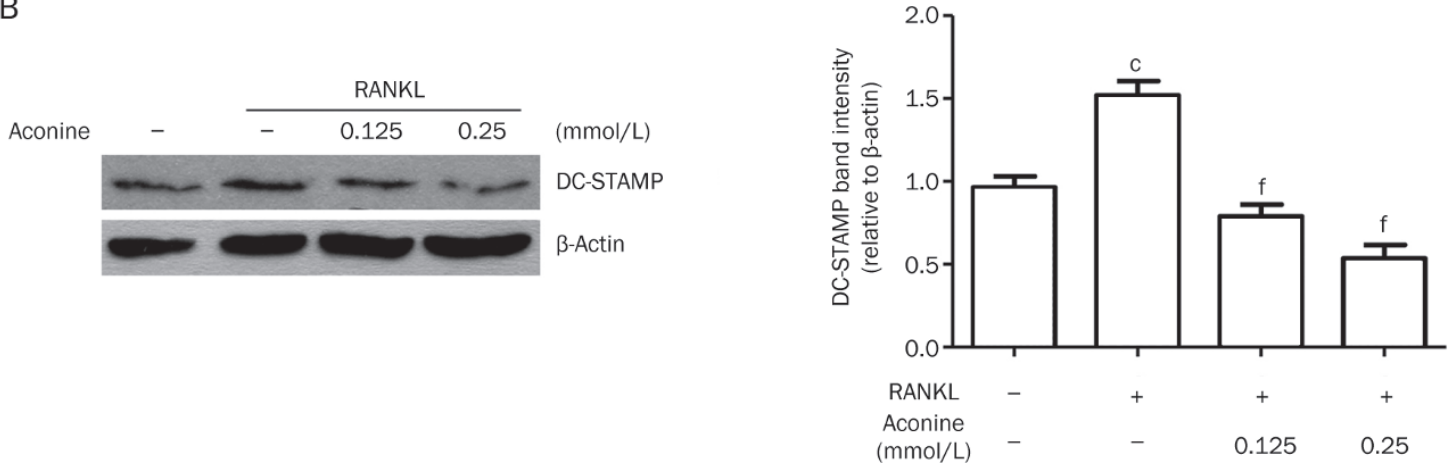

Figure 7. Aconine decreases the expression level of the fusion molecule DC-STAMP. RAW264.7 cells were pretreated with varying concentrations of aconine for $2 \mathrm{~h}$ and then treated with RANKL (100 ng/mL) for $24 \mathrm{~h}$. (A) DC-STAMP mRNA levels were analyzed using real-time PCR. (B) The protein levels of DC-STAMP were determined using Western blot analysis. Protein levels were quantified using densitometry. Mean \pm SEM. $n=3$. ${ }^{\mathrm{b}} P<0.05$, ${ }^{\mathrm{c}} P<0.01$ vs control; ${ }^{\mathrm{e}} P<0.05,{ }^{\mathrm{f}} P<0.01$ vs only RANKL-treated cells.

dependently inhibits RANKL-induced osteoclast differentiation and function in pre-osteoclastic RAW264.7 cells by downregulation the RANKL-induced activation of the transcription factors NF-KB and NFATc1 and repressing the expression level of the fusion molecule DC-STAMP. However, further investigations into the precise mechanisms by which aconine suppresses osteoclastogenesis are still required.

\section{Acknowledgements}

This work was supported by National Natural Science Foundation of China (81073119 and 81373123) to Xiao-juan LI and a Guangdong Pearl River Scholar Funded Scheme to Shu-wen LIU.

\section{Author contribution}

Xiao-juan LI, Xiang-zhou ZENG and Shu-wen LIU designed the research; Xiang-zhou ZENG, Song WANG, Long-gang HE, Keng WANG, Yue-yang ZHANG and Lei TAO performed the research; Xiang-zhou ZENG and Song WANG analyzed the data; and Xiang-zhou ZENG, Xiao-juan LI and Shu-wen LIU wrote the paper.

\section{References}

1 Boyle WJ, Simonet WS, Lacey DL. Osteoclast differentiation and activation. Nature 2003; 423: 337-42.
2 Kukita T, Wada N, Kukita A, Kakimoto T, Sandra F, Toh K, et al. RANKL-induced DC-STAMP is essential for osteoclastogenesis. J Exp Med 2004; 200: 941-6.

3 Walsh MC, Kim N, Kadono Y, Rho J, Lee SY, Lorenzo J, et al. Osteoimmunology: interplay between the immune system and bone metabolism. Annu Rev Immunol 2006; 24: 33-63.

4 Takayanagi H. Osteoimmunology: shared mechanisms and crosstalk between the immune and bone systems. Nat Rev Immunol 2007; 7: 292-304.

5 Negishi-Koga T, Takayanagi H. $\mathrm{Ca}^{2+}$-NFATc1 signaling is an essential axis of osteoclast differentiation. Immunol Rev 2009; 231: 241-56.

6 Zeng Z, Zhang C, Chen J. Lentivirus-mediated RNA interference of DCSTAMP expression inhibits the fusion and resorptive activity of human osteoclasts. J Bone Miner Metab 2013; 31: 409-16.

7 Islam R, Bae HS, Yoon WJ, Woo KM, Baek JH, Kim HH, et al. Pin1 regulates osteoclast fusion through suppression of the master regulator of cell fusion DC-STAMP. J Cell Physiol 2014; 229: 2166-74.

8 Zhang C, Dou CE, Xu J, Dong S. DC-STAMP, the key fusion-mediating molecule in osteoclastogenesis. J Cell Physiol 2014; 229: 1330-5.

9 Yagi M, Miyamoto T, Sawatani Y, Iwamoto K, Hosogane N, Fujita N, et al. DC-STAMP is essential for cell-cell fusion in osteoclasts and foreign body giant cells. J Exp Med 2005; 202: 345-51.

10 Tong $\mathrm{P}$, Wu C, Wang X, Hu H, Jin H, Li C, et al. Development and assessment of a complete-detoxication strategy for Fuzi (lateral root of Aconitum carmichaeli) and its application in rheumatoid arthritis therapy. J Ethnopharmacol 2013; 146: 562-71.

11 Zhang HG, Sun Y, Duan MY, Chen YJ, Zhong DF, Zhang HQ. Separation 
and identification of Aconitum alkaloids and their metabolites in human urine. Toxicon 2005; 46: 500-6.

12 Chan TY. Aconite poisoning. Clin Toxicol 2009; 47: 279-85.

$13 \mathrm{Kim} \mathrm{MH}$, Shim KS, Kim SH. Inhibitory effect of cantharidin on osteoclast differentiation and bone resorption. Arch Pharm Res 2010; 33: 457-62.

14 Li X, He L, Hu Y, Duan H, Li X, Tan S, et al. Sinomenine suppresses osteoclast formation and Mycobacterium tuberculosis H37Ra-induced bone loss by modulating RANKL signaling pathways. PLoS One 2013; 8: e74274.

15 Xiao W, Beibei F, Guangsi S, Yu J, Wen Z, Xi H, et al. Iron overload increases osteoclastogenesis and aggravates the effects of ovariectomy on bone mass. J Endocrinol 2015. doi:10.1530/joe-140657.

16 Singh PP, van der Kraan AG, Xu J, Gillespie MT, Quinn JM. Membranebound receptor activator of NFkappaB ligand (RANKL) activity displayed by osteoblasts is differentially regulated by osteolytic factors. Biochem Biophys Res Commun 2012; 422: 48-53.

17 Kim MH, Ryu SY, Choi JS, Min YK, Kim SH. Saurolactam inhibits osteoclast differentiation and stimulates apoptosis of mature osteoclasts. J Cell Physiol 2009; 221: 618-28.

18 Park KH, Park B, Yoon DS, Kwon SH, Shin DM, Lee JW, et al. Zinc inhibits osteoclast differentiation by suppression of $\mathrm{Ca}^{2+}$-CalcineurinNFATc1 signaling pathway. Cell Commun Signal 2013; 11: 74.

19 He LG, Li XL, Zeng XZ, Duan H, Wang S, Lei LS, et al. Sinomenine induces apoptosis in RAW264.7 cell-derived osteoclasts in vitro via caspase-3 activation. Acta Pharmacol Sin 2014; 35: 203-10.
20 Asagiri M, Takayanagi $\mathrm{H}$. The molecular understanding of osteoclast differentiation. Bone 2007; 40: 251-64.

21 Boyce BF, Xing L, Franzoso G, Siebenlist U. Required and nonessential functions of nuclear factor-kappa B in bone cells. Bone 1999; 25: 137-9.

22 Takayanagi $\mathrm{H}$. The role of NFAT in osteoclast formation. Ann N Y Acad Sci 2007; 1116: 227-37.

23 Song I, Kim JH, Kim K, Jin HM, Youn BU, Kim N. Regulatory mechanism of NFATc1 in RANKL-induced osteoclast activation. FEBS Lett 2009; 583: 2435-40.

24 Wei ZF, Tong B, Xia YF, Lu Q, Chou GX, Wang ZT, et al. Norisoboldine suppresses osteoclast differentiation through preventing the accumulation of TRAF6-TAK1 complexes and activation of MAPKs/NFkB/c-Fos/NFATc1 pathways. PLoS One 2013; 8: e59171.

25 Costa AG, Cusano NE, Silva BC, Cremers S, Bilezikian JP. Cathepsin $\mathrm{K}$ : its skeletal actions and role as a therapeutic target in osteoporosis. Nat Rev Rheumatol 2011; 7: 447-56.

26 Broadhead ML, Clark JCM, Dass CR, Choong PFM, Myers DE. Therapeutic targeting of osteoclast function and pathways. Expert Opin Ther Targets 2011; 15: 169-81.

27 Yagi M, Miyamoto T, Toyama Y, Suda T. Role of DC-STAMP in cellular fusion of osteoclasts and macrophage giant cells. J Bone Miner Metab 2006; 24: 355-8.

28 Chiu YH, Mensah KA, Schwarz EM, Ju Y, Takahata M, Feng C, et al. Regulation of human osteoclast development by dendritic cell-specific transmembrane protein (DC-STAMP). J Bone Miner Res 2012; 27: 79-92. 